period runs through all the recorded observations of sun-spots since the telescope came to be used. And furthermore it appears that these eleven-yearly oscillations are not always of the same magnitude; sometimes they are large, and sometimes small. They were probably small about the middle of last century, becoming large towards the end of it ; they were again small about the early part of the present century. They have recently been large, and we may suspect that in future there will again be a falling off.

Besides exhibiting this complicated periodicity, sun-spots have many other characteristics, the most prominent of which I will now bring before you. Of these the most peculiar is a proper motion of their own. If there were no sun-spots it would be very difficult to determine the elements of the sun's rotation. Accordingly sun-spots have been used for this purpose ever since the telescope was invented. They are carried by the solar rotation from east to west across the visible disk of the sun in about thirteen days, and hence we may conclude that the sun, roughly speaking, rotates round its axis in twice thirteen, or twenty-six days. But Carrington found that spots move fastest when nearest the solar equator, and slowest when nearest the solar poles; and in consequence of this proper motion of spots there is an uncertainty as to the exact period of solar rotation. Another point of interest is the distribution of spots over the solar surface. There are never any at or near the sun's poles, the zone in which they break out having its limits about $30^{\circ}$ on each side of the equator. It might be expected from this that we should have a maximum of spots close to the equator, but such is not the case. There are very few at the equator, the maximum number corresponding to a solar latitude of about $15^{\circ}$ north or south. We must not however conclude that spots invariably exhibit a preference for this latitude, for Carrington has shown that on certain occasions they appear by preference to seek a higher latitude, widening out on each side of the solar equator simultaneously, while at other times they prefer a lower latitude, coming together towards the equator simultaneously on each side.

Dr. Smysloff of the Wilna Observatory has likewise observed a sort of hemispherical see-saw in the behaviour of spots. Sometimes they prefer the northern hemisphere of the sun-at other times the southern; but this observer is inclined to think that if we pursue our researches for a length of time sufficiently great we shall find an equal amount of spots in each hemisphere.

I have thus endeavoured to bring before you the fact that sun-spots exhibit curiously complicated laws of a roughly periodical nature. Two questions arise from this discussion: the one is of a theoretical nature, and has reference to the possible causes of this behaviour; while the other is of great practical 25 well as of theoretical interest, and has reference to the effect which these strange solar phenomena produce upon the mag. netism and meteorology of the earth and upon the general well. being of the human race.

To be continued.

\section{PROF. ALLMAN ON THE DEVELOPMENT OF THE CTENOPHORA}

$I^{N}$ accordance with his usual practice of making his anniverI sary address at the Linnean Society an exposition of recent progress in certain departments of zoological research, the President on this occasion (24th May, 1881) selected as his subject the advances which, during late years, had been made in our knowledge of the development of the Ctenophora.

He referred especially to the beautiful researches of Alexander Agassiz, and to those of Fol, Kowalewsky, and most recently of Chun. He pointed out the phenomenon to which he was the first to call attention, that immediately after the earliest stages of the egg cleavage a remarkable peculiarity shows itself, in the fact that the continued cleavage is no longer uniform, but takes place much more energetically in certain cleavage spheres than in others, whereby the former are broken up into a multitude of small cells, which gradually envelop the latter, thus giving us at this early period of embryonic development the foundation of the two germinal leaflets, ectoderm and endoderm. He showed, how the body thus formed becomes excavated by an internal cavity, which soon communicates by an orifice with the exterior, thus presenting, as shown especially by the researches of Chun, the condition of a gastrula; how the gastrula-mouth becomes afterwards closed by the continued extension over it of the ectoderm; how a new orifice, the permanent Ctenophoremouth, makes its appearance at the opposite hole, the ectoderm here becoming invaginated, so as to form the permanent stomach which opens into the central cavity, which becomes the "funnel" from which spring all the vessels which are destined to distribute the nutritive fluid through the body; how, in the spot formerly occupied by the gastrula-mouth, certain cells of the ectoderm become differentiated, so as to form the rudimental nervous system; and how the great vascular trunks are formed by the differentiation of portions of the endoderm, into which offsets extend from the central cavity.

Prof. Allman further referred to the facts connected with the metamorphoses which the larvæ of the Ctenophora undergo between the moment of leaving the egg and the attainment of the mature form-facts for which we are mainly indebted to the researches of Alexander Agassiz and of Chun. He showed how the lobed section of the Ctenophora, as proved by the investigations of A. Agassiz on Bolina, and by those of Chun on Eucharis, are at first quite destitute of the "lobes" which constitute so characteristic a feature in the adult; and how the young Ctenophore has at this time all the characters of the more simply constructed Cydipidæ, Eucharis being also compressed like a Mertensia in the direction of the stomach axis, while in the adult the compression of the body is at right angles to this ; how the lobes afterwards grow out laterally from the oral side of the body; how the meridional vessels at first ending in blind extremities extend themselves into the rudimental lobes, and there form the anastomoses and rich convolutions which become so striking in the adult, the stomach vessels finally entering into the anastomoses.

$\mathrm{He}$ also referred to Chun's remarkable discovery of the sexually-mature condition of the very early larva of Eucharis, from which was reared a young brood which returned to the larvæ form from which it originated.

Chun's observations on the metamorphoses of the Venus's girdle (Cestum Veneris) were also dwelt on. It was shown how the young cestum had a nearly globular form, and possessed all the essential features of the Cydipidæ, so that notwithstanding the extremely aberrant characters of the adult the young may be taken as affording a type of the gastro-vascular system, with the distribution of the vessels in the Ctenophora generally. The gradual extension of the Cydippe-like larva in the direction of the funnel-plane changes it into the long, flattened, band-like form of the adult, and brings about (with modifications in the number and direction of the swimming-plates, and the substitution of new tentacles to replace those of the larva which had disappeared) the singularly aberrant course of the vessels characteristic of the mature Venus's girdle.

\section{UNIVERSITY AND EDUCATIONAL INTELLIGENCE}

Cambridge.-Mr. J. W. Clark is to be re-appointed Superintendent of the Museums of Comparative Anatony and Zoology for two years, at the end of which time the Council of the Senate appear to anticipate that some fresh arrangements as to this office may be made.

Mr. W. Hillhouse, Assistant Curator of the Herbarium, will give a course of lectures on Morphology and Systematic Botany during July and August, suited to candidates for the Natural Sciences Tripos. In connection with the course there will be practical work in the Gardens and Botanical Laboratory; and a botanical excursion will be made, weather permitting, on Wednesday in each week.

Dublin.-The Professors of the Medical School in Trinity College have, at the suggestion and with the sanction of the Rev. Dr. Hanghton, the senior lecturer of the College, introduced into their summer courses of lectures, to a very large extent, practical instruction, instead of the time-honoured and now somewhat antiquated series of prelections. These summer courses chiefly consist of Chemistry, Histology, Botany, Comparative Anatomy, and Operative Surgery. In the Chemistry, instead of listening as formerly to an hour's lecture three times each week, the students work in the laboratory under the superintendence of Prof. Emerson Reynolds, F.R.S., for two hours every alternate day, and on one day in each week attend a demonstration by the Professor on the analysis of water, air, and articles of food. In the Histology Prof. Purser gives a lecture on one day in each week, at the close of which illustrative preparations are shown in the laboratory. On the other days the students are engaged on practical work in the new physiological laboratory, where, as in the chemi- 
cal laboratory, each student has his own place, with full set of apparatus and reagents. The laboratory is open from II a.m. to $5 \mathrm{p} . \mathrm{m}$. In Botany, Prof. E. Perceval Wright gives the first ten lectures to the class in the lecture-room, on the general details of the structure and morphology of floweringplants. The second part of the course consists of ten demonstrations on such forms as Bacteria, Yeast-mucor, Saprolegnia, Oidium, Mushroom, the Algx"; and the remaining portion is given in the College Botanical Gardens, when each student is required to bave a practical acquaintance with a certain number of natural families. The demonstrations in Comparative Anatomy are conducted by Prof. Macalister, F.R.S., who is fortw. nate in having the resources of the gardens of the Zoological Society to assist in the practical work of his class. So far as the experiment has this session gone, the results have been most happy, the students showing a far greater interest in their work, and the demonstrations being less formal than the lectures, they have greater facilities for asking questions.

THE fiftieth anniversary of the foundation of the Technische Hochschule at Hanover is being celebrated during this week. Numerous guests from all parts of Germany, as well as from England, Sweden, Norway, the Netherlands, and Russia have arrived at Hanover.

\section{SCIENTIFIC SERIALS}

Fournai of the Academy of Natural Sciences of Philadelphia, vol. 7, second series, part $4,1874-1881$. -Wm. M. Gabb, descriptions of Caribbean Miocene fossils; descriptions of new species of fossils from the Pliocene clay-beds between Iimon and Moen, Costa Rica, together with notes on previously known species from there and elsewhere in the Caribbean area (with four plates).--Andrew Garrett, on the terrestrial mollusea inhabiting the Cook's or Harvey Islands.-Dr. C. Chapman, the placenta and generative apparatus of the elephant (with three plates).-Dr. Joseph Leidy, on some parasites of the Termites (gives full descriptions, with figures, of the strange forms briefly described in the Proceedings of the Academy of Natural Sciences, P hiladelphia, for 1877. Trichonympha agilis is a truly extraordinary form, possibly a protozoan intermediate between the Gregarines and Infusoria).-Dr. Joseph Leidy, remarks on Bathygnathus borealis.

Zeitschrift für wissenschaftliche Zoologie, Bd. 35, Heft 3, 1881.-Dr. J. W. Spengel, the organ of smell and nervous system in the mollusca, a contribution to our knowledge of the unity of the molluscan plan (plates 17, I9). - Dr. O. Bitschli. Short contributions to a knowledge of the Gregarines: (I) on the development of Gregarina (Clepsidrina) blattarum; (2) on the power of adhering in Monocystis magna, and on the pseudo. navicella in the monocysts of the earth-worm; (3) on some eggshaped Psorospermia in the intestine of Lithobius forficatus (plates 20,21).-Prof. F. E. Schulze, researches on the structure and development of sponges, $x$. On Corticium candelabrum, Schdt. (plate 22). -Dr. A. Gruber, on the process of division in Euglypha alveolata (plate 23).-B. Ulianin, on the development in amphipods (plate 24).-Dr. Paul Fraisse, on molluscan eyes with an embryonal type (plates 25 and 26) (Patella, Haliotis, Fissurella).-Dr. P. A. Loos, on the albaminiferous glands in amphibia and birds (plate 27).

Atti della $R$. Accademia delle Scienze Fisiche e Matematiche, Napoli, vol. vii.-F. Panceri, the phosphorescence and the phos* phorescent organs in some Annellida (Chætopterus, Balanoglossus, Polynoe), plates 1 to 4 .- On the seat of the phosphorescence in some Campanularia (with a plate), and observations of some new species of marine nematoid worms (Desmoscolex elongatus and $D$. lanuginosus, Echinoderes meridionalis, $E$. minutus, $E$. eruca, and $E$ spinosus, Tristicocheta inarimerse, n.gen. et n.sp. near Chætosoma); all the new species are figured. -A. Costa, notes of a visit to Egypt, Palestine, and the coasts of Turkey (zoological). - V. Cesati, on a new species of Battarræa (B. Guicciardiniana), with a plate.-On a collection of Pterydophytes made at Borneo by Signor D. Beccari, with plates.-G. Licopoli, on the fruit of the vine and its chief constituents, with a plate. -G. A. Pasquale, on a new species of Lonicera ( $L$. stabiana), with a plate.-F. Gasco, account of the whale (Balena Biscayensis, Esch.) captured at Taranto on February 9,1877 , with 9 plates. $-G$. Battaglini, on projective geometry.-E. Fergola, on the dimensions of the earth.-G.
Nicolucci, the Cola grotto near Petrella di Cappadocia, in the province of Abruzzi, with three plates of animal remains.-On prehistoric researches about the environs of the Lake of Lesina. -L. Palmieri, on the present condition of electrical meteorology.

\section{SOCIETIES AND ACADEMIES \\ LONDON}

Royal Society, May 12.- "Investigations on the spectrum of magnesium," by Professors Liveing and Dewar.

The flame of magnesium burning in air shows strongly, generally well reversed, the line at wave-length 2850 (Cornu); a strong triplet, resembling in the relative distance of its lines the other magnesium triplets, close to the solar line $M$; the wellknown triplet near $\mathrm{L}$; and a remarkable series of lines and bands, generally resembling the spectra of some compounds, extending from $M$ to between $L$ and $K$. Neither the strong triplet at $M$ nor this series of bands are represented in the spectrum of magnesium either in the arc or spark. These flame. lines are remarkable as further evidence of the power of substances to emit, at comparatively low temperatures, radiations of short wave-length.

In the arc the authors notice a series of triplets, of which the least refrangible lines have wave-lengths about 2767,2736 , $2798,2673,2649,2633$ respectively. These, with the wellknown triplets $b$, and those near the solar lines $L, P$, and $S$, form a series, similar to those described by the authors in the spectra of sodium, potassium, and lithium in which the alternate members are sharp and diffuse, and succeed one another at shorter and shorter intervals in a way which indicates that they follow a definite law and are probably harmonically related, though not forming a simple harmonic series. They observe that the line w.l. 2850 is the strongest line of magnesium both in the flame and arc, and one of the strongest in the spark, and that it is nearly the octave of the line some time since observed by them at wave-length about 5710. They observe in the arc only the strongest two of the quadruple group described by Cornu from the spark at wave. lengths 2801,2795 , but they notice both in arc and spark a group of five lines a little higher at wave-lengths about 2782 , $278 \mathrm{r}, 2779,2778,2777$. All these lines, including the diffuse members of the series of triplets, they have often observed reversed when the arc is taken in one of their crucibles. The line w.l. about 4570 , so conspicuous in the flame, first noticed by the authors in the spark, is well seen and easily reversed in the arc, and they believe it to be represented in the solar spectrum by the line w.l. $4570^{\circ} 9$ in Angström's map. Besides these lines they observe in the arc a pair of lines slightly less refrangible than the pair in the spark, described by Cornu near the solar line U. In the spark they observe two pairs of ghost-like lines below the triplet near L, which together with the fainter two of the quad. ruple group (280I, \&c.), seem to suggest the lpossibility that some of the particles of magnesium have, owing to particular circumstances, their tones a little flattened in regard to these particular vibrations, though the constancy in the amount of displacement of the lines militates against such an hypothesis.

In regard to the $b$ group, observations on the spectrum of the fourth order given by a Rutherford grating of 17296 lines to the inch showed that the iron line in $b_{4}$ is a little less refrangible than the magnesium line. The additional lines near this group observed by Fievez they ascribe to a periodic inequality in the ruling of the Rutherford grating, arising from an imperfection of the screw of the ruling machine, which praduces a series of ghosts on either side of each principal line. The positions of these ghosts have been investigated mathematically by Peirce (Math. Fournal of John Hopkins University), and observations of them tally with the theory. They are embarrassing in the case of bright lines, but may be detected by their changes of position in the spectra of different orders.

The magnesium-hydrogen spectrum which the authors have previously investigated and found to be produced at ordinary and reduced pressures when both elements are present, but not otherwise, they have now investigated further by observing the spark discharge between magnesium poles in hydrogen, nitrogen, and carbonic oxide, at pressures varying from one to twenty atmospheres. They find that in hydrogen, when no Leyden jar is used, the peculiar fluted spectrum of magnesium hydrogen is much more brilliant at higher pressures, becoming fully equal in brightness to the $b$ group, notwithstanding the increase in 